\title{
Photocatalytic degradation of dyes by using a membrane reactor
}

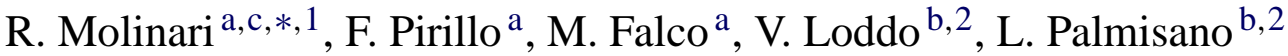 \\ a Dipartimento di Ingegneria Chimica e dei Materiali, Università della Calabria, via P. Bucci, Cubo 45a, I-87030 Rende (CS), Italy

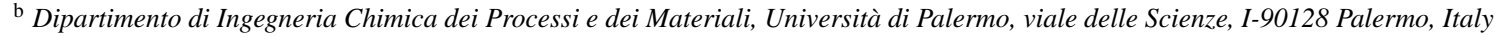 \\ c Institute on Membrane Technology, ITM-CNR, c/o University of Calabria, via P. Bucci, Cubo 17/c, I-87030 Rende (CS), Italy
}

Received 17 April 2003; received in revised form 18 November 2003; accepted 4 January 2004

Available online 24 May 2004

\begin{abstract}
Dyes are organic compounds used in textile, food and drug industries, and their abatement represents one of the main problems in the treatment

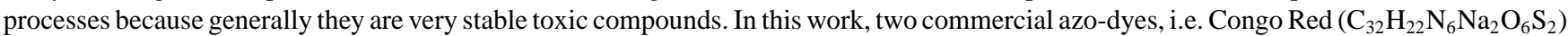
and Patent Blue $\left(\mathrm{C}_{27} \mathrm{H}_{31} \mathrm{~N}_{2} \mathrm{NaO}_{6} \mathrm{~S}_{2}\right)$, in aqueous solution were degraded in a photocatalytic membrane reactor by using TiO $\mathrm{O}_{2}$ Degussa P25 as the catalyst. Different system configurations and irradiating sources were studied, and the influence of some operational parameters such as the pressure in the membrane cell and the initial concentration of the substrates was determined. A comparison between suspended and entrapped $\mathrm{TiO}_{2}$ was also done. The experimental results showed a satisfactory degradation efficiency of the photocatalytic membrane process. The influence of various parameters (e.g. feed concentration, recirculation rate) has been discussed to obtain high reaction rates, operating stability and high membrane rejection, both for substrates and by-products. Congo Red was photodegraded with higher rate under the same experimental conditions probably due to its higher adsorption onto the catalyst surface. It was possible to treat successfully highly concentrated solutions $(500 \mathrm{mg} / \mathrm{L})$ of both dyes by means of a continuous process obtaining good values of permeate fluxes $\left(30-70 \mathrm{~L} / \mathrm{m}^{2} \mathrm{~h}\right)$; this could be interesting for industrial applications. The reactor containing the suspended photocatalyst was significantly more efficient than the reactor containing the catalyst entrapped into the membrane.
\end{abstract}

(C) 2004 Elsevier B.V. All rights reserved.

Keywords: Membrane photoreactors; Degradation of dyes; Water purification

\section{Introduction}

Dyes are organic compounds characterised by the presence of unsaturated groups (chromophores) in the molecule structure, which consist of double and triple bonds as $-\mathrm{C}=\mathrm{C}-,-\mathrm{N}=\mathrm{N}-,-\mathrm{C} \equiv \mathrm{N}-$, whose function is to shift the radiation absorption in the visible range. Other functional groups characterising this class of compounds are the auxochromes ones as $-\mathrm{NH}_{2},-\mathrm{OH},-\mathrm{COOH},-\mathrm{SO}_{3} \mathrm{H}$ responsible for the increase of the colour intensity and of the affinity with the fibres. More than 30,000 commercial dyes based on ca. 8,000 different chemical structures are used in textile

\footnotetext{
* Corresponding author. Tel.: +39-0984-496699; fax: +39-0984-496655.

E-mail addresses: r.molinari@unical.it (R. Molinari), palmisan@dicpm.unipa.it (L. Palmisano).

${ }_{1}$ Tel.: +39-0984-492025; fax: +39-0984-402103.

2 Tel.: +39-091-6567246; fax: +39-091-6567280.
}

(60\%), food, pharmaceutical, paper and ink industries, and usually they are discharged in waste water. Azo-dyes represent the most common dyes actually employed in textile industries, and a relevant problem is related to the presence of these products in the environment [1].

Waste water derived from industrial plants that use dyes in their processes needs suitable treatments before its release in order to avoid dangerous increase of BOD and COD in rivers or in drainage areas. Moreover, effluent streams coming from textile plants contain toxic or carcinogenic residues together with their by-products. The treatments are focussed not only to solve the environmental impact but also to allow water and dyes reuse.

In order to meet the limitation imposed by the current legislation [2], these effluents are usually treated by physico-chemical, oxidative or, most commonly, active sludge biochemical processes. The main drawback of the above processes is that they generally produce secondary pollution due to the introduction of chemicals and/or the 
possible accumulation of other bio-resistant species in the environment. The solubility of azo-dyes in water is generally scarce (it is usually inversely proportional to the molecular complexity of the structure of the dye) so that only few azo-dyes can be oxidised aerobically. Generally, they are degraded anaerobically to give aromatic amines that are successively degraded under aerobic conditions. Homogeneous oxidation treatments are generally effective towards the destruction of the chromophore structures and the water decolouration, but a complete mineralisation of the dye is often not achieved.

As an alternative or an integration to the conventional processes, advanced oxidation technologies have been proposed. Bleaching of dyes has been carried out by using ozone [3], photo-Fenton type reactions [4] or a reduction followed by a photo-oxidation process [5].

In particular, possible applications of heterogeneous photocatalysis have been investigated [6-10]. The fundamentals of this method, described in the literature cited, can be summarised as follows: the irradiation of solid semiconductors by light of suitable energy causes electron excitation from the valence band to the conduction band, generating electron-hole pairs that can react with water and dissolved oxygen to form various oxidising species such as hydroxyl superoxide and perhydroxyl radicals. These highly reactive oxygen-containing species are able to oxidise organic molecules, leading to their complete mineralisation. If the substrate is a dye, its photosensitisation upon excitation by visible light can occur [11]. Recent studies concerning the photocatalytic oxidation of azo-dyes in aqueous wastes showed encouraging results [11-18].

Membrane separation processes have been studied in order to reuse waste water derived from textile industries by means of nano and ultrafiltration of dye baths [19-21] or they have been coupled with other technologies as for instance the ozonation [22].

In the last years, hybrid processes based on membranes (reverse osmosis, nanofiltration, ultrafiltration, microfiltration) and photocatalysis have been studied. The membrane technology combined with the photocatalytic one seems to be suitable for waste water treatment. Indeed, membranes could play the role of support for the photocatalyst and, if a suitable membrane is used, of selective barrier for the species to be degraded $[23,24]$.

This study reports the photodegradation process of two commercial azo-dyes, the Patent Blue and the Congo Red, in a membrane photoreactor by using suspended $\mathrm{TiO}_{2}$ as the photocatalyst and a nanofiltration membrane as separation barrier acting at molecular level. Different system configurations and irradiating sources were studied, and the influence of some operational parameters such as the pressure in the membrane cell and the initial concentration of the substrates was determined. A comparison between suspended and entrapped $\mathrm{TiO}_{2}$ was also carried out. The performances of the whole process like retentate flow rate, membrane rejection, degradation kinetics in batch and continuous configurations were investigated.

\section{Experimental}

Commercial Patent Blue $\left(\mathrm{C}_{27} \mathrm{H}_{31} \mathrm{~N}_{2} \mathrm{NaO}_{6} \mathrm{~S}_{2}\right)$ and Congo Red $\left(\mathrm{C}_{32} \mathrm{H}_{22} \mathrm{~N}_{6} \mathrm{Na}_{2} \mathrm{O}_{6} \mathrm{~S}_{2}\right)$ dyes (provided by Sigma-Aldrich) in solutions of deionised water were used; their structures are shown in Figs. 1 and 2. The following analytical grade reagents (Sigma-Aldrich): cellulose triacetate (CTA), 2-nitrophenyl octyl ether (2-NPOE), and methyl chloride $\left(\mathrm{CH}_{3} \mathrm{Cl}\right)$ were used as received to prepare membranes with entrapped titanium dioxide.

$\mathrm{TiO}_{2} \mathrm{P} 25$ Degussa (surface area ca. $50 \mathrm{~m}^{2} \mathrm{~g}^{-1}$ and size of the primary particles around $30 \mathrm{~nm} \mathrm{[6])} \mathrm{was} \mathrm{used} \mathrm{in} \mathrm{all}$ the photocatalytic experiments.

Commercial nanofiltration membranes NTR 7410 (Nitto Denko, Tokio) were used in the rejection and photocatalytic degradation experiments. They were made of sulphonate polyethersulphone polymer with a $600 / 800 \mathrm{Da}$ cut-off and the following characteristics from the manufacturer: rejection $10 \%$ in the presence of $0.2 \%(\mathrm{w} / \mathrm{w}) \mathrm{NaCl}$ at a pressure of $4.9 \mathrm{bar}$, a temperature of $25^{\circ} \mathrm{C}$ and a pH equal to 6.5. After each run, the membranes were regenerated by immersing them for $15 \mathrm{~h}$ in $200 \mathrm{~mL}$ of an aqueous solution containing $0.5 \%(\mathrm{w} / \mathrm{w})$ of an enzymatic detergent (Ultrasil 50 by Henkel).

Cellulose triacetate membranes with entrapped $\mathrm{TiO}_{2}$ $\left(\mathrm{CTA}-\mathrm{TiO}_{2}-\mathrm{Al}-10\right)$ were home prepared by using the phase inversion process: $0.07 \mathrm{~g}$ of polymer (CTA) was slowly added to the solvent $\left(\mathrm{CH}_{3} \mathrm{Cl}\right)$ at $40^{\circ} \mathrm{C}$. The solution was maintained under agitation for $3 \mathrm{~h}$, and then the plasticizer (2-NPOE; $2-\mathrm{NPOE} / \mathrm{CTA}=100 \%$, v/v) and the $\mathrm{TiO}_{2}$ $\left(\mathrm{TiO}_{2} /\left(\mathrm{TiO}_{2}+\mathrm{CTA}\right)=50 \%, \mathrm{w} / \mathrm{w}\right)$ were added. The mixture was mixed for $12 \mathrm{~h}$, and then it was placed in a Petri plate for $24 \mathrm{~h}$ at room temperature to allow the evaporation

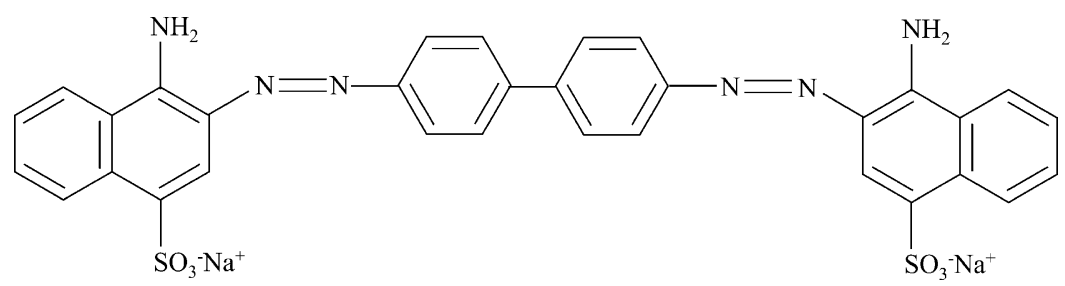

Fig. 1. Chemical structure of Congo Red. 


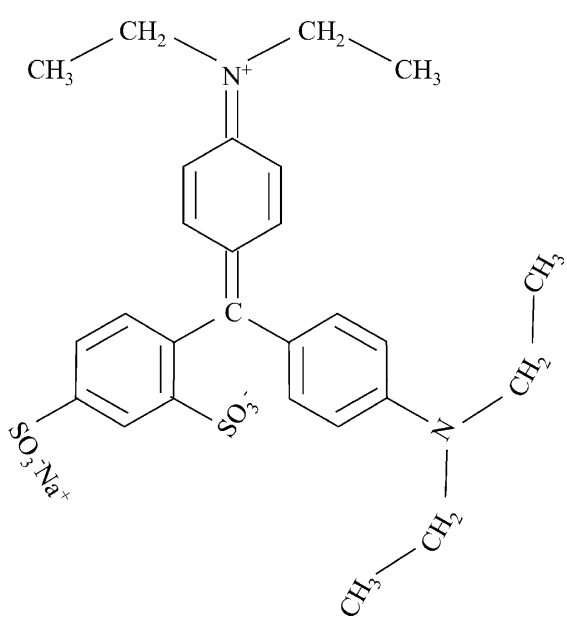

Fig. 2. Chemical structure of Patent Blue.

of the solvent and the occurrence of the polymerisation process.

In order to determine the best reacting system configuration, some experimental runs were carried out by using Congo Red in two types of batch photoreactors (without membrane): a cylindrical photoreactor with external lamp and an annular one with immersed lamp. In Fig. 3, the scheme of the system using the external lamp is reported. The photoreactor $(500 \mathrm{~mL}$ volume) was equipped with a (e)

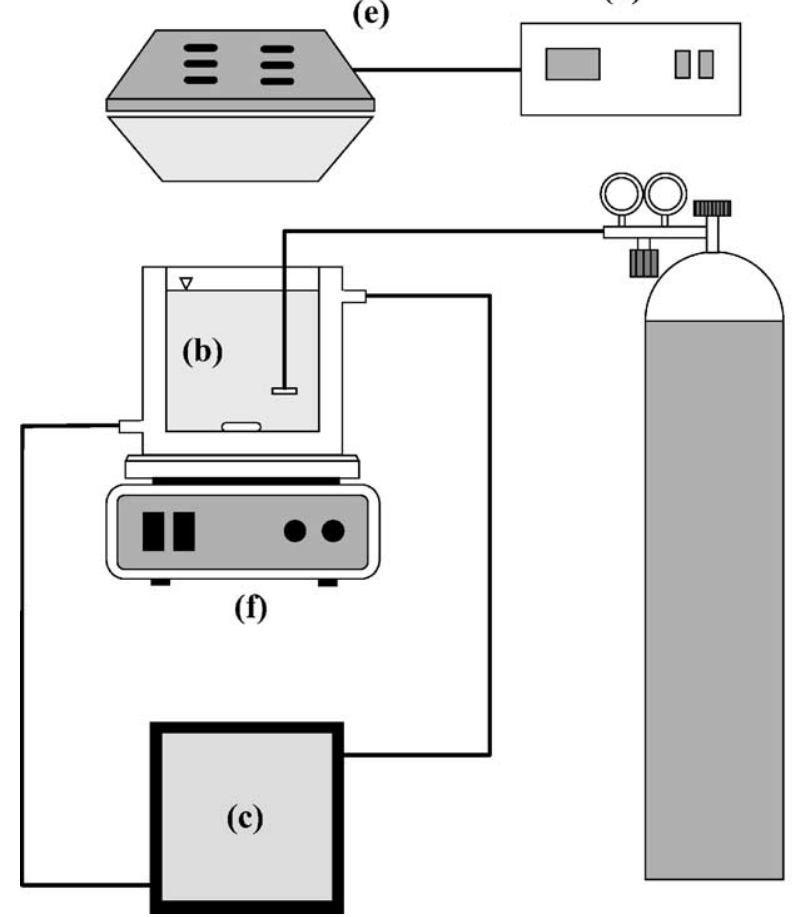

cooling jacket and a thermostatted bath in order to maintain the temperature at $30^{\circ} \mathrm{C}$. A $500 \mathrm{~W}$ Helios Italquartz (Milan) medium pressure $\mathrm{Hg}$ lamp placed on the top of the reactor $(5 \mathrm{~cm}$ from the dispersion) was used as the irradiating source. The photocatalyst was maintained in suspension by means of a magnetic stirrer. Oxygen was continuously bubbled from a cylinder by means of a horizontal microfiltration tubular polypropylene membrane (internal diameter $0.5 \mathrm{~cm}$, length $3 \mathrm{~cm}$, mean pore size $0.2 \mu \mathrm{m}$ ).

The scheme of the system using the immersed lamp is reported in Fig. 4. The annular photoreactor, whose volume was $500 \mathrm{~mL}$, had ports in its upper section for sampling the suspension and bubbling of gas. A $125 \mathrm{~W}$ medium pressure Hg lamp (Helios Italquartz, Milan), placed in a cylindrical cooling jacket Pyrex made, was positioned axially inside the reactor, which was filled with the aqueous dispersion containing the catalyst and the dye. Oxygen was continuously bubbled by using the same membrane before described.

For both systems, the same experimental conditions were used, i.e. initial Congo Red concentration $40 \mathrm{mg} / \mathrm{L}$; oxygen concentration $20 \mathrm{mg} / \mathrm{L}$; catalyst amount $1 \mathrm{~g} / \mathrm{L}$; initial $\mathrm{pH}$ 6.42. In all the experiments, the lamp was switched on after 30 min of mixing in the dark (to allow the saturation of the dispersion with oxygen and the achievement of steady-state conditions for the adsorption phenomena), and then samples were withdrawn at fixed intervals of time.

When the membrane was used, the photodegradation and rejection experiments on both dyes were carried out in the

(a)

Fig. 3. Scheme of the batch system with external lamp used in the experimental runs without membrane with the catalyst suspended: (a) oxygen cylinder; (b) cylindrical reactor with cooling jacket; (c) thermostatic bath with cooling water; (d) power supply; (e) medium pressure Hg lamp $(400 \mathrm{~W})$ with conic reflector; (f) magnetic stirrer. (d)

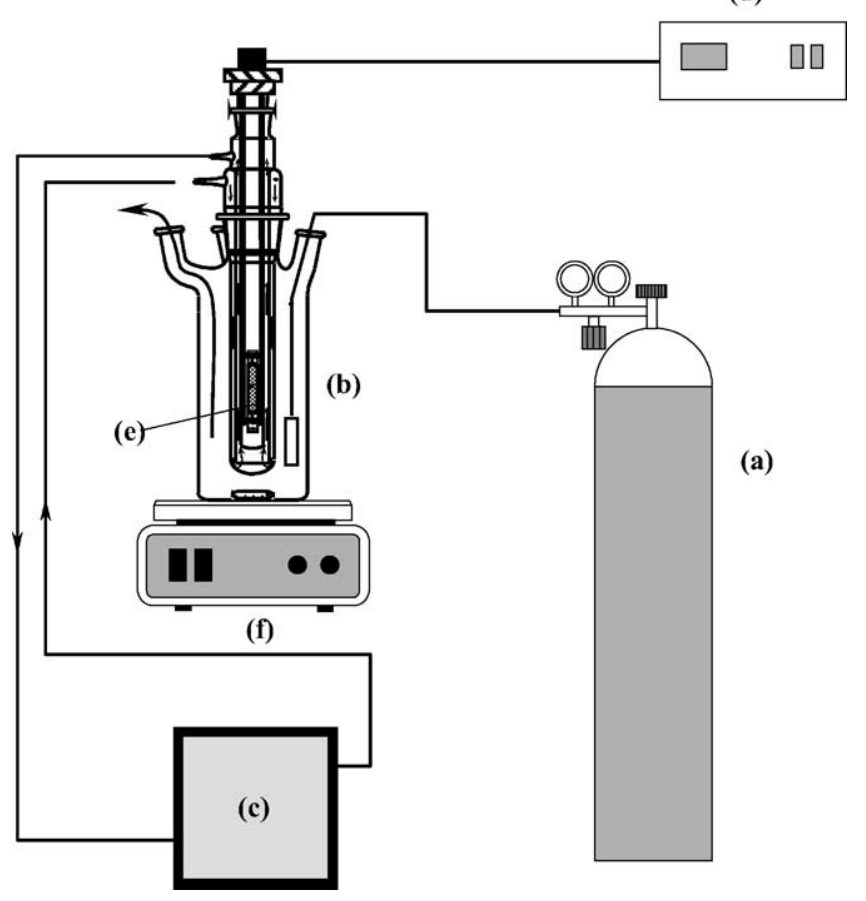

Fig. 4. Scheme of the batch system with immersed lamp used in the experimental runs without membrane with the catalyst suspended: (a) oxygen cylinder; (b) cylindrical reactor; (c) thermostatic bath with cooling water; (d) power supply; (e) medium pressure Hg lamp (125 W) with cooling jacket; (f) magnetic stirrer. 


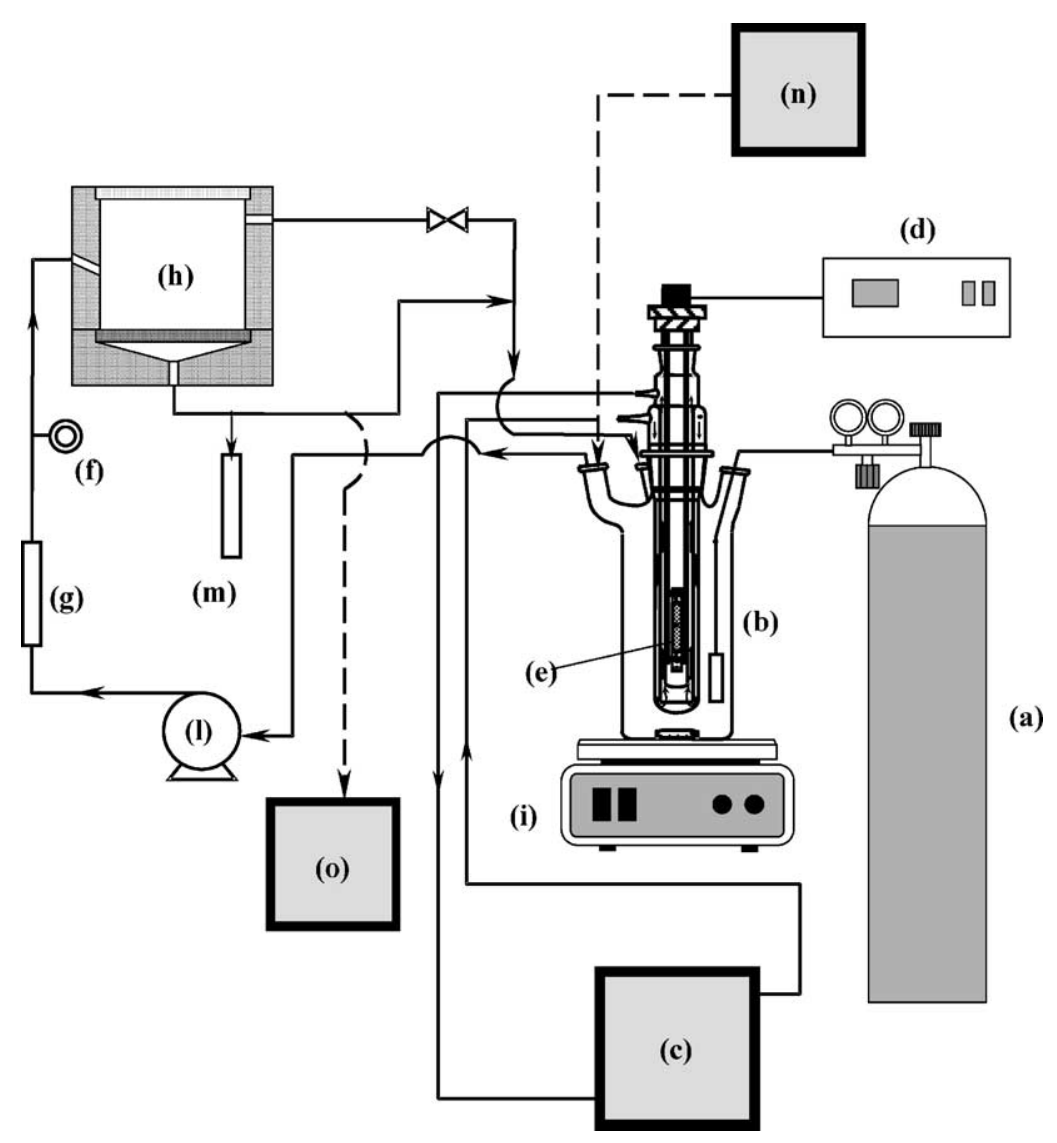

Fig. 5. Scheme of the system used with membrane and suspended catalyst: (a) oxygen cylinder; (b) photoreactor; (c) thermostatic bath with cooling water; (d) power supply; (e) medium pressure $\mathrm{Hg}$ lamp with cooling jacket; (f) manometer; (g) rotameter; (h) pressurised cell containing the membrane; (i) magnetic stirrer; (l) pump; (m) graduated cylinder for permeate sampling; (n) feed tank (continuous regime); (o) waste tank (continuous regime).

system shown in Fig. 5. This was built by coupling the membrane cell to the photocatalytic reactor with immersed lamp (see Fig. 4). The nanofiltration membrane was placed on a porous disk of sintered stainless steel in the bottom of a cylindrical cell made with the same material. The cell (95 $\mathrm{mL}$ volume) was maintained under pressure by means of a diaphragm pump (Cole-Palmer: $Q=360 \mathrm{~L} \mathrm{~h}^{-1} ; P_{\max }$ 14 bar) equipped with an AISI 316 stainless steel head. The pressure in the cell was regulated by means of a valve in the retentate line. The suspension entered the cell downward tangentially, generating a turbulence which minimised catalyst sedimentation onto the surface of the membrane and left the cell from the top. All the tubing used was stainless steel made to avoid adsorption of the organic species.

The CTA- $\mathrm{TiO}_{2}-\mathrm{Al}-10$ membranes were tested in the system shown in Fig. 6. This system differs from the previous one because the membrane with entrapped photocatalyst was directly irradiated and the irradiation was performed by an external lamp through the Pyrex window of the membrane cell. The collecting tank in this case was the same cylindrical vessel with cooling jacket previously described in Fig. 3 .

Before starting the batch photoreactivity runs, the rejection of NTR-7410 membrane to the two dyes was tested. It was determined by using $500 \mathrm{~mL}$ of an aqueous solution con- taining the dye $(40 \mathrm{mg} / \mathrm{L})$ at $30^{\circ} \mathrm{C}$ and pressures of 3.5 and 6 bar. Membrane rejection $(R \%)$ was calculated by means of its definition, i.e. $R \%=\left(1-\left(C_{\mathrm{p}} / C_{\mathrm{r}}\right)\right) \times 100$, where $C_{\mathrm{p}}$ and $C_{\mathrm{r}}$ are the permeate and the retentate concentrations of substrate, respectively.

All the photoreactivity runs were carried out with the following criteria. The concentrations of the dye in the retentate and permeate were periodically analysed, and when steady-state conditions were reached, the catalyst was added to the system and oxygen was bubbled. After $30 \mathrm{~min}$ (time needed for oxygen saturation of the suspension), the lamp was switched on and samples were periodically withdrawn.

Photocatalytic runs in a quasi-continuous mode were also carried out in the system of Fig. 5. Volumes of $10 \mathrm{~mL}$ of fresh dye solution at a concentration of $500 \mathrm{mg} / \mathrm{L}$ were fed step-by-step when a same volume of permeate was withdrawn from the system.

$\mathrm{TiO}_{2}$ deposition on NTR-7410 membrane was tested at different pressures $(0,3.5$ and 7 bar) by recirculating in the system $500 \mathrm{~mL}$ of an aqueous suspension of $\mathrm{TiO}_{2}(1 \mathrm{~g} / \mathrm{L})$ and by measuring periodically the absorbance at $600 \mathrm{~nm}$ (turbidity) in the retentate suspension containing the catalyst. A linear dependence of turbidity was found in the range $0-0.3 \mathrm{~g} / \mathrm{L}$, and it was used as calibration curve to determine 
(e)

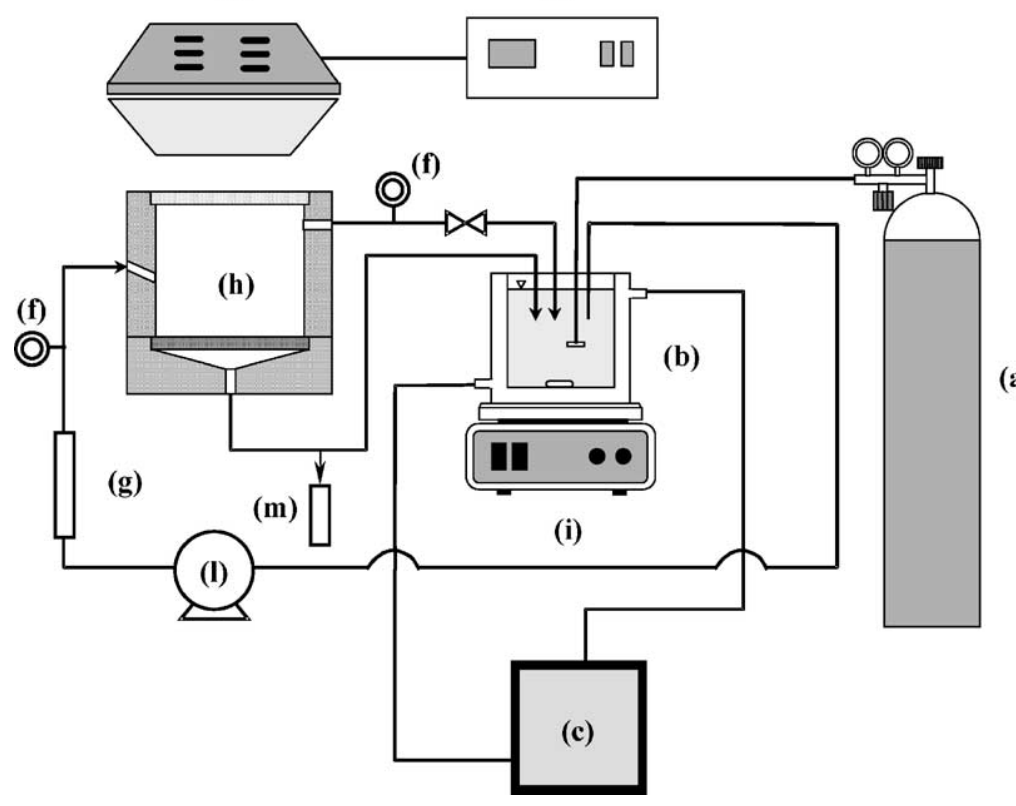

(d)

(a)

Fig. 6. Scheme of the batch system used with membrane and entrapped catalyst: (a) oxygen cylinder; (b) cylindrical reactor with cooling jacket; (c) thermostatic bath; (d) power supply; (e) medium pressure Hg lamp with conic reflector; (f) manometer; (g) rotameter; (h) cell containing the membrane; (i) magnetic stirrer; (1) pump; (m) graduate cylinder for permeate sampling.

the amount of the not photo-activated $\mathrm{TiO}_{2}$ present in the recycling loop.

In order to compare the systems with entrapped $\mathrm{TiO}_{2}$ (CTA-TiO $2-\mathrm{Al}-10$ membranes) and that with suspended $\mathrm{TiO}_{2}$, some runs were carried out by using the same amount of photocatalyst and an external illumination (see Figs. 3 and 6). The mass of $\mathrm{TiO}_{2}$ used in suspension $\left(m_{\text {sus }}\right)$ was equal to the amount of entrapped solid in the membrane exposed to the radiation $\left(m_{\exp }\right)$ calculated by considering the following relationships:

$m_{\text {sus }}=m_{\exp }$

$m_{\mathrm{exp}}=\left(\frac{m_{\mathrm{tot}}}{S_{\mathrm{m}}}\right) S_{\mathrm{exp}}$

$S_{\mathrm{m}}=\frac{\pi D_{\mathrm{in}}^{2}}{4}$

where $m_{\mathrm{tot}}$ is the total amount of catalyst added to the solution containing the precursors of the membrane, $S_{\exp }$ is the surface of the membrane effectively irradiated, $S_{\mathrm{m}}$ is the total membrane surface, $D_{\text {in }}$ is the internal diameter of the Petri plate in which the membrane was produced.

The concentrations of dye were determined by measuring the absorbance by means of a spectrophotometer (Shimadzu UV 160A) at a wavelength of 498 and $639 \mathrm{~nm}$ for Congo Red and Patent Blue, respectively. All the samples used were filtered by means of a membrane (mean pore size $0.22 \mu \mathrm{m}$ ) before carrying out the analyses. No presence of absorption bands of intermediates interfering with those of the disappearing substrates was observed at the used wavelengths. Total organic carbon (TOC) measurements of filtered and not-filtered samples were carried out by using the DR. LANGE (Gesamter, Organischer Kohlenstoff, Germany) method with a LT 100 thermostat and a LASA 100 photometer. The $\mathrm{pH}$ measurements were carried out by means of an EA 920 (Orion Research) pH meter and an $\mathrm{Ag}-\mathrm{AgCl}$ (Mettler Toledo DG11 SC) electrode.

\section{Results and discussion}

In order to identify the most efficient radiant system between those shown in Figs. 3 (external lamp) and 4 (immersed lamp), two runs in similar experimental conditions were carried out by using Congo Red. A photodegradation rate of $0.274 \mathrm{mg} / \mathrm{min}$ with the immersed lamp compared to $0.00548 \mathrm{mg} / \mathrm{min}$ using the external lamp was found. It means that Congo Red was photo-degraded much more quickly (ca. 50 times) when the immersed lamp was used, although the power of the last was ca. four times lower than that of the external lamp. Consequently, the experiments were mainly carried out by using the immersed lamp.

Preliminary runs were performed under the same experimental conditions in the presence and in the absence of $\mathrm{TiO}_{2}$ for both dyes to investigate the extent of possible homogeneous processes. As far as Congo Red is concerned, no evidence of homogeneous photodegradation was found, while concerning Patent Blue, it was noticed (Fig. 7) that the reaction rate for the run carried out in the presence of $\mathrm{TiO}_{2}$ was much more higher (ca. one order of magnitude) than that observed in the homogeneous system. This finding indicates a not-significant contribution of the homogeneous 


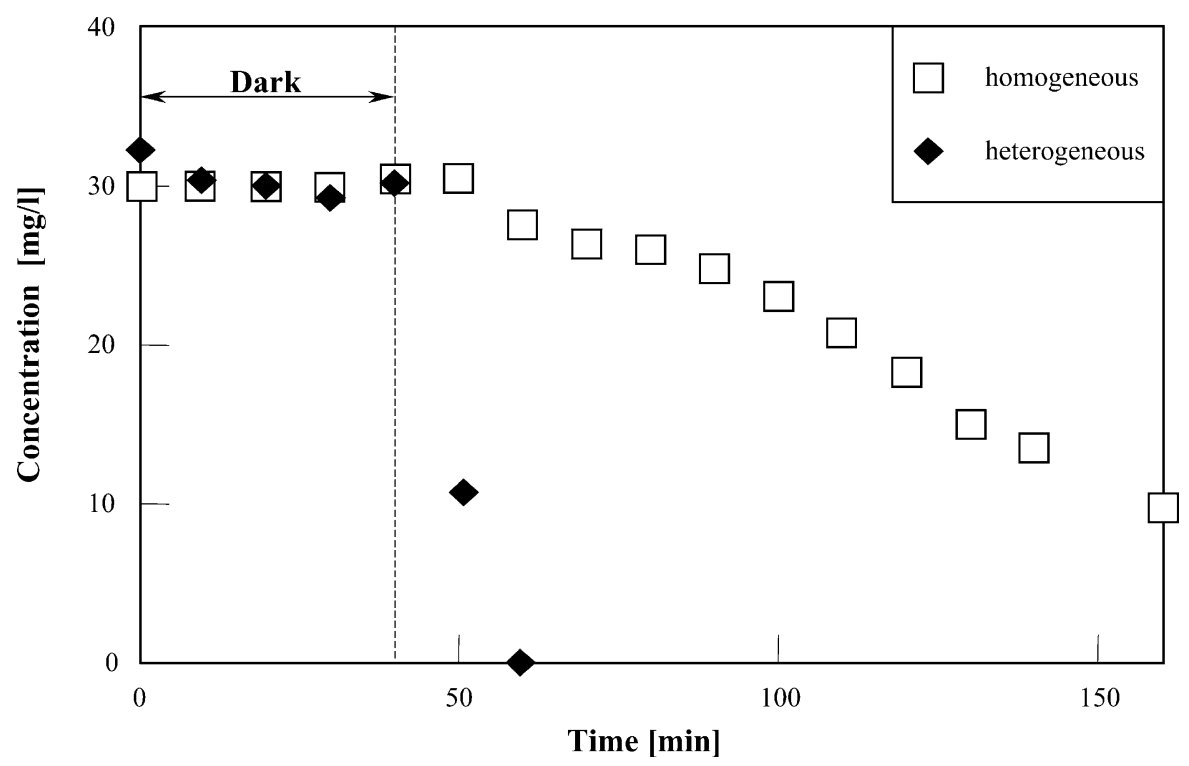

Fig. 7. Patent Blue concentration versus time for two runs carried out in the presence or in the absence of $\mathrm{TiO}_{2}$ by using the set-up shown in Fig. 4 $\left(V=500 \mathrm{~mL} ; T=303 \mathrm{~K} ; \mathrm{C}\left(\mathrm{O}_{2}\right)=22 \mathrm{ppm} ; \mathrm{TiO}_{2}\right.$ amount $=1 \mathrm{~g} / \mathrm{L}$; lamp: $125 \mathrm{~W}$ medium pressure $\mathrm{Hg}$ immersed lamp; initial $\left.\mathrm{pH} 5.61\right)$.

process. Another preliminary aspect studied was the correlation between spectrophotometric and TOC measurements of dyes concentration. The results of the photodegradation tests in batch on both dyes showed a strict correlation between these two kinds of measurement for concentrations higher than $2 \mathrm{mg}$ TOC/L and higher than $0.5 \mathrm{mg}$ dye/L. Consequently, the concentration of the dye versus time was followed by measuring the absorbance due to the simplicity of the method.

The effect of the initial concentration of Patent Blue on the photodegradation rate was studied in the batch system with immersed lamp (see Fig. 4), and the results of var- ious runs are reported in Fig. 8. After a first step during which the dye was adsorbed onto the catalyst surface (in the dark), it was observed that for concentrations higher than ca. $100 \mathrm{mg} / \mathrm{L}$, the data well fitted zero-order kinetics with similar slopes of the plots (observed rate constant equal ca. $1.7 \mathrm{mg} / \mathrm{L} \mathrm{min}$ ), which turned to pseudo-first-order kinetics for lower concentrations. This behaviour is well known in photocatalysis, and it can be explained by hypothesising a Langmuir-Hinshelwood kinetics in which a complete coverage of the active surface of the catalyst occurs at the highest values of concentrations, while first-order kinetics prevails at low coverage [8].

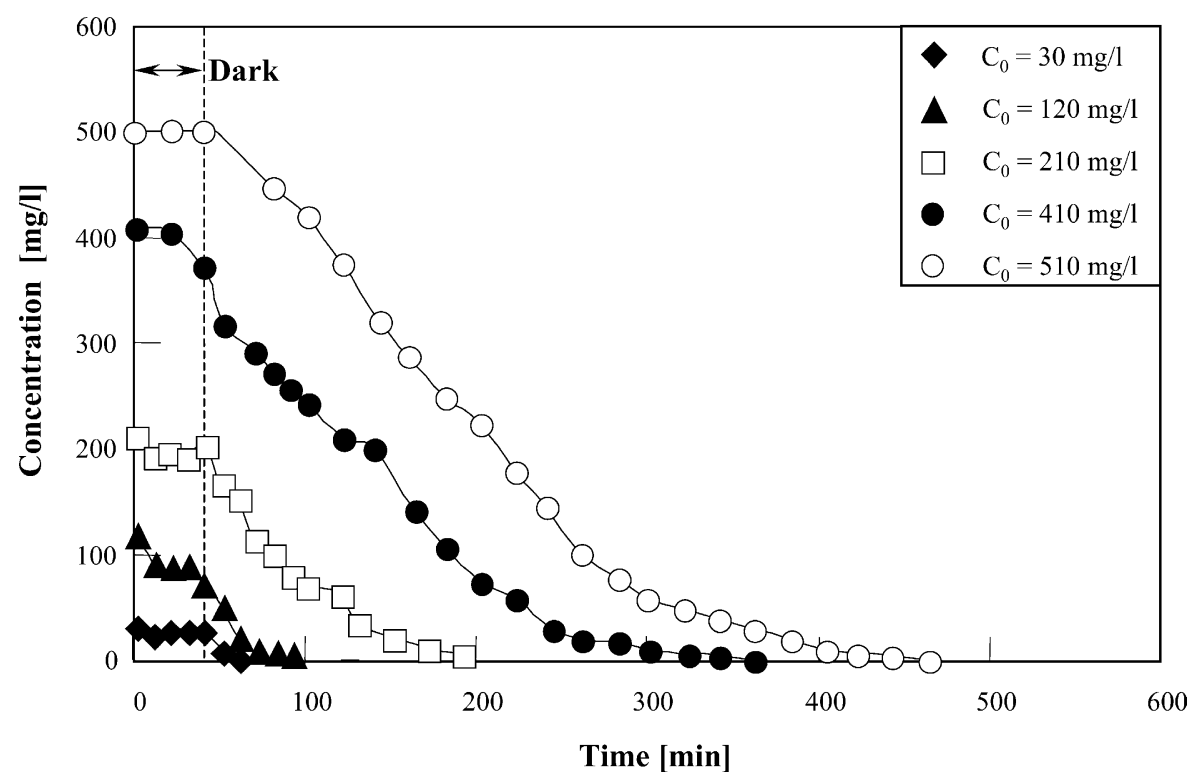

Fig. 8. Patent Blue concentration versus time for runs carried out at different initial concentrations by using the set-up shown in Fig. 4 . ( $V=500 \mathrm{~mL}$; $T=303 \mathrm{~K} ; \mathrm{C}\left(\mathrm{O}_{2}\right)=22 \mathrm{ppm} ; \mathrm{TiO}_{2}$ amount $=1 \mathrm{~g} / \mathrm{L}$; lamp: $125 \mathrm{~W}$ medium pressure $\mathrm{Hg}$ immersed lamp; initial $\left.\mathrm{pH} 5.61\right)$. 


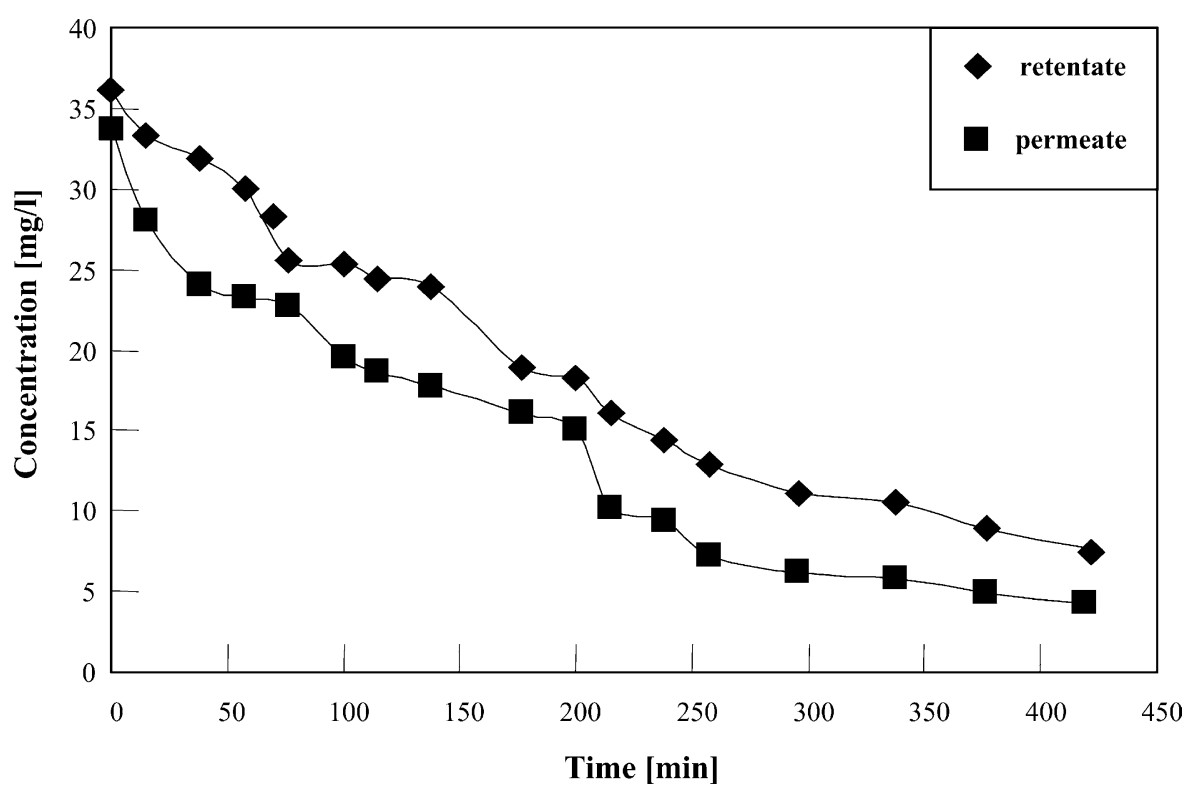

Fig. 9. Patent Blue concentration vs. time when the set-up shown in Fig. 5 was used. $\left(V=500 \mathrm{~mL} ; T=303 \mathrm{~K} ; \mathrm{C}_{0}=36 \mathrm{mg} / \mathrm{L} ; \mathrm{C}\left(\mathrm{O}_{2}\right)=22 \mathrm{ppm} ; \mathrm{TiO} 2\right.$ amount $=1 \mathrm{~g} / \mathrm{L}$; lamp: $125 \mathrm{~W}$ medium pressure $\mathrm{Hg}$ immersed lamp; initial $\mathrm{pH} 5.61 ; \Delta P=6$ bar; tangential flow rate $=450 \mathrm{~mL} / \mathrm{min}$; permeate flux at steady-state conditions $=39.0 \mathrm{~L} / \mathrm{h} \mathrm{m}^{2}$ ).

In order to achieve a better control of the residence time of the dyes during the photodegradation process, a hybrid photoreactor was used in which the nanofiltration membrane was able to selectively confine both dye and catalyst in the reaction ambient while the permeate was withdrawn. The results and the experimental conditions used for a representative run carried out with Patent Blue in the membrane photoreactor with suspended catalyst (see Fig. 5) are reported in Fig. 9. The photodegradation reaction follows pseudo-first-order kinetics (observed rate constant equal to $\left.3.76 \times 10^{-3} \mathrm{~min}^{-1}\right)$. A similar run carried out in the absence of membrane (figure not reported for the sake of brevity) by using the set-up of Fig. 4 showed an observed rate constant of $1.02 \times 10^{-2} \mathrm{~min}^{-1}$. The reason of the lower photodegradation rate in the presence of the membrane will be explained in the following.

Two additional runs, under the same experimental conditions used for Patent Blue, were carried out with Congo Red, but this substrate showed an almost complete adsorption onto the catalyst surface, indicating a strong interaction with the solid. Indeed, both substrate concentration and total organic carbon determinations carried out after separation of the photocatalyst were virtually zero even at the start of the run. In this case, TOC determinations without filtration of the sample enabled to solve the analytical problem and to follow the photoprocess. Fig. 10 reports TOC values along with the colour of the samples versus irradiation time (set-up Fig. 4). The photodegradation reaction follows zero-order kinetics (observed rate constant equal to $0.245 \mathrm{mg} / \mathrm{L} \mathrm{min}$ ), and correspondingly, the colour changed from purple to off-white. Despite the fact that the colour of the suspension was off-white to naked eye, the presence of colourless organic intermediates and/or small quantities of the starting substrate cannot be excluded. The complete mineralisation of the dye was not achieved after $35 \mathrm{~min}$, but an almost complete photodegradation occurred after a prolonged irradiation (TOC value $2.88 \mathrm{mg} / \mathrm{L}$ after $80 \mathrm{~min}$ ). Moreover, it is worth noting that Congo Red was directly analysed spectrophotometrically when its amount in solution was higher than that adsorbed onto the catalyst.

A very similar variation of colour (from purple to off-white) for a run carried out under the same experimental conditions in the presence of the membrane (set-up in Fig. 5) occurred after $47 \mathrm{~min}$, indicating that the photodegradation rate in the absence of membrane was more efficient. The higher rate observed for Congo Red with respect to Patent Blue can be explained by considering the almost complete adsorption of the first dye onto the catalyst surface.

The lower reaction rates for both dyes obtained by using the membrane with respect to that obtained in its absence were due to the smaller volume of irradiated suspension (320 against $500 \mathrm{~mL})$ because a part $(180 \mathrm{~mL})$ circulated in the pipes of the plant and in the membrane cell. The possible drawback of the deposit of the catalyst into the cell containing the membrane was also studied. An aqueous suspension of $\mathrm{TiO}_{2}$ was circulated in the set-up shown in Fig. 5, and the turbidity at different times and at different values of pressure (retentate flow rate decreased by increasing the pressure) was measured. The experimental results reported in Fig. 11 indicate that absorbance initially decreased for each $\Delta P$ value and then reached an almost constant value. A steady-state absorbance value was achieved very quickly at the highest retentate flow rate $(0 \mathrm{bar})$. By using the calibration straight line of the turbidity, it was possible to know the 


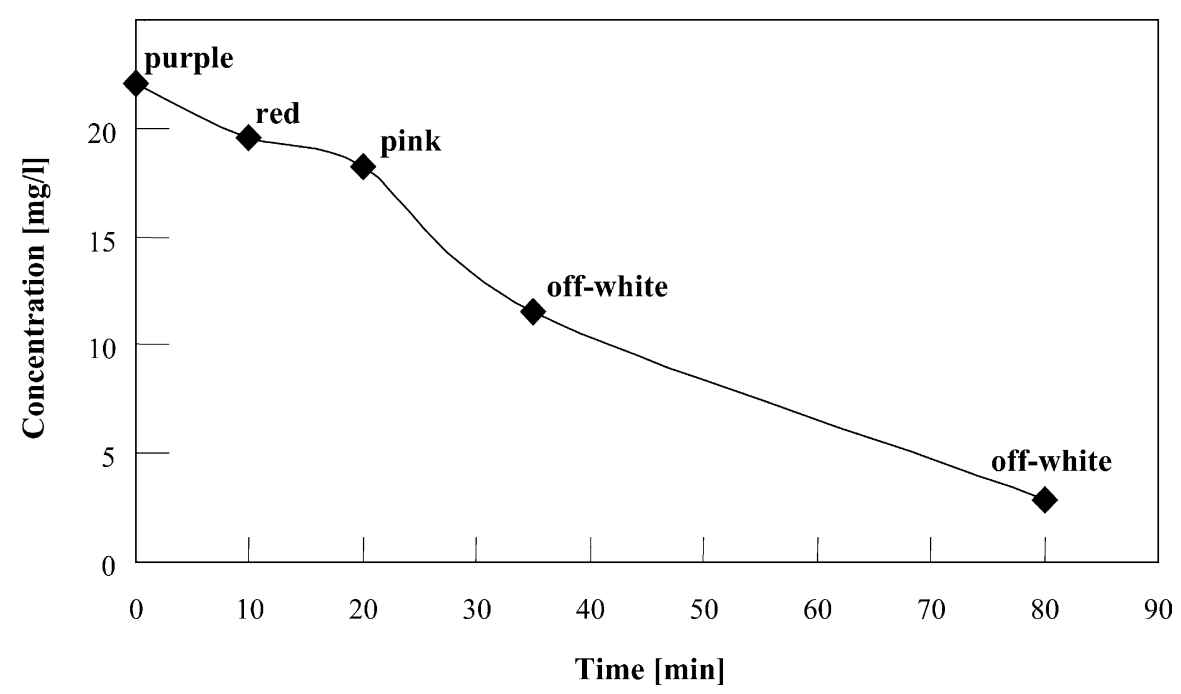

Fig. 10. Congo Red total organic carbon (TOC) concentration without separation of the catalyst and colour of the suspension versus time by using the set-up shown in Fig. $4\left(V=500 \mathrm{~mL} ; T=303 \mathrm{~K} ; \mathrm{C}_{0}=40 \mathrm{mg} / \mathrm{L} ; \mathrm{C}_{\left(\mathrm{O}_{2}\right)}=22 \mathrm{ppm} ; \mathrm{TiO}_{2}\right.$ amount $=1 \mathrm{~g} / \mathrm{L}$; lamp: $125 \mathrm{~W}$ medium pressure $\mathrm{Hg}$ immersed lamp; initial pH 5.93).

percentage of the not photo-activated catalyst in the external recycle $(35 \%, \mathrm{w} / \mathrm{w})$ for a photodegradation experiment carried out in the same set-up. This value was in agreement with the percentage (36\%) calculated by taking into account the not-irradiated volume $(180 \mathrm{~mL})$ with respect to the total volume $(500 \mathrm{~mL})$.

The possibility to treat successfully highly concentrated solutions of both dyes was examined, allowing the set-up shown in Fig. 5 to work as a continuous system. In particular, the transient condition in the membrane photoreactor was studied by separating the effects of accumulation, adsorption and photodegradation. Results of three runs with Congo Red for which the initial concentration of pollutant inside the photoreactor was zero are reported in Fig. 12. The first run, carried out in the absence of UV light and photocatalyst, indicated that the initial rate of dye accumulation in the photoreactor was $0.151 \mathrm{mg} / \mathrm{min}$. The second run, carried out in the absence of UV light but in the presence of $\mathrm{TiO}_{2}$, indicated that no increase of dye concentration occurred in the photoreactor during the first 45 min of continuous working of the plant because $40 \mathrm{mg}$ of Congo Red fed $(80 \mathrm{~mL}$ of $500 \mathrm{mg} / \mathrm{L}$ dye solution) was adsorbed onto the catalyst surface. After saturation of the catalyst was reached, the concentration of the dye in the retentate increased linearly with an accumulation rate of $0.136 \mathrm{mg} / \mathrm{min}$, very close to that determined for the first run. In the third run, the continuous degradation of Congo Red in the presence of UV light and catalyst was performed and concentrations in the retentate

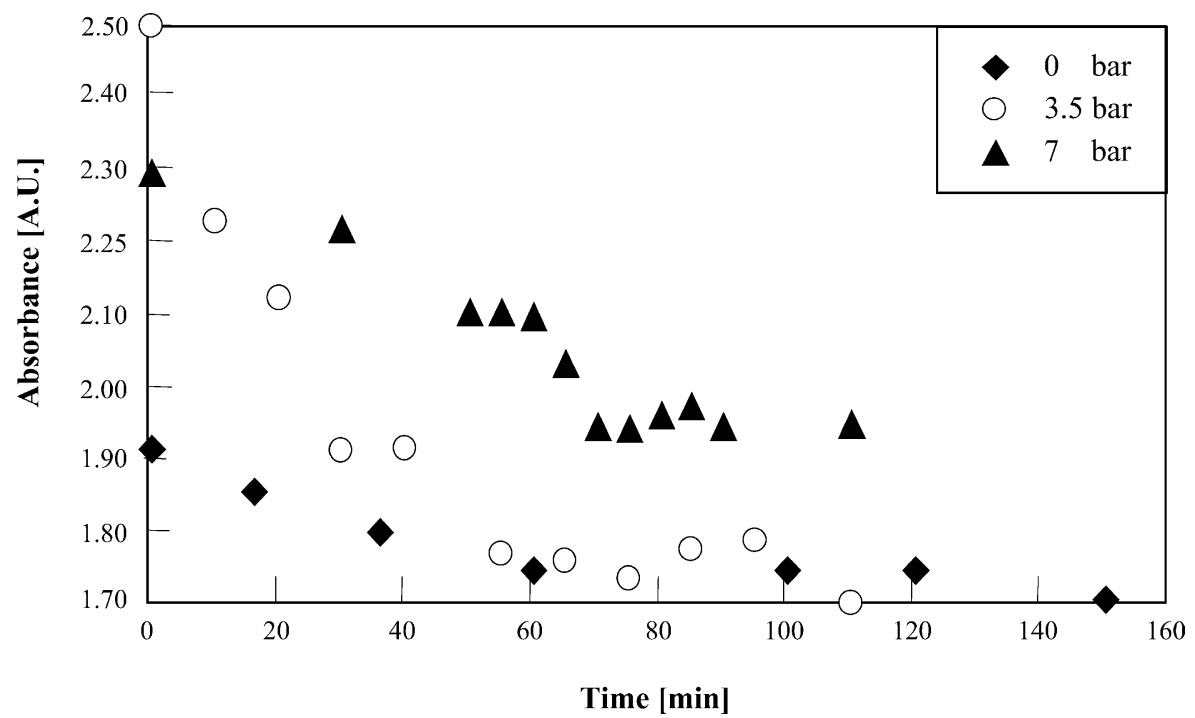

Fig. 11. Absorbance of the retentate consisting of a suspension of $\mathrm{TiO}_{2}$ Degussa $\mathrm{P} 25$ versus circulation time at different $\Delta P$ values $(V=500 \mathrm{~mL}$; $T=303 \mathrm{~K} ; \mathrm{TiO}_{2}$ amount $=1 \mathrm{~g} / \mathrm{L} ;$ membrane: NTR-7410). 


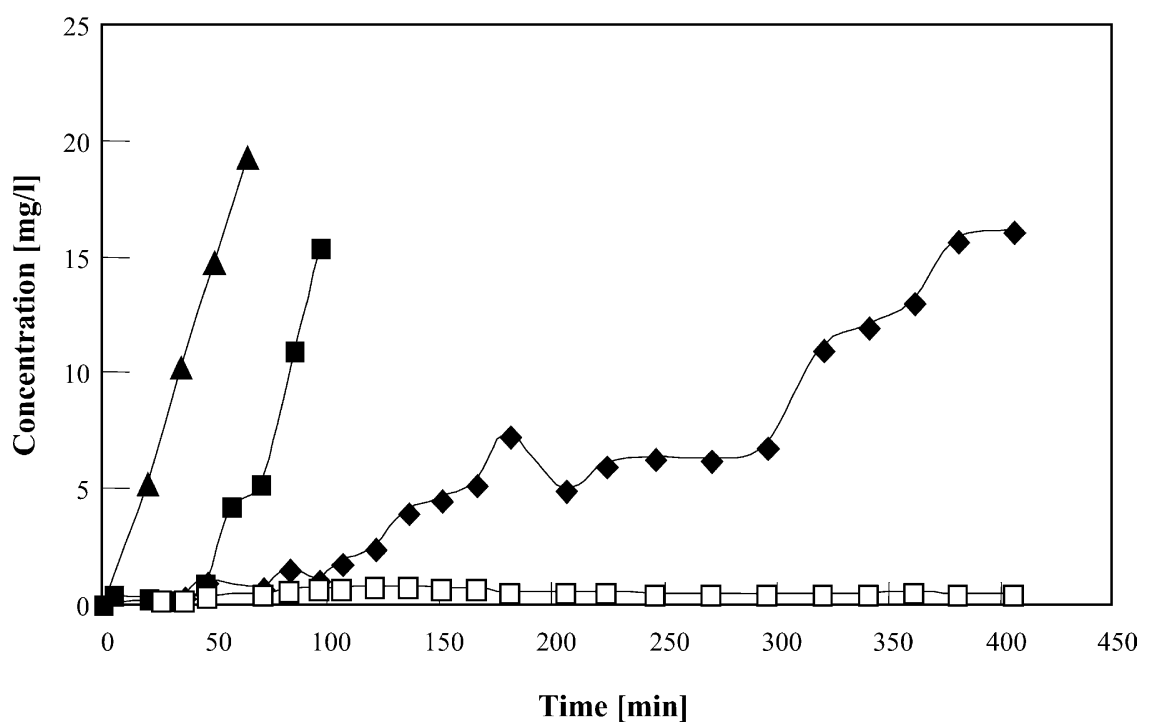

Fig. 12. Concentration of Congo Red in the retentate and in the permeate versus time for three different continuous runs: in the absence of UV light and $\mathrm{TiO}_{2}(\boldsymbol{\Delta})$; in the absence of UV light but in the presence of $\mathrm{TiO}_{2}(\boldsymbol{\square})$; in the presence of UV light and $\mathrm{TiO}_{2}:(\diamond)$ retentate; $(\square)$ permeate. $(V=500 \mathrm{~mL}$; $T=303 \mathrm{~K} ; \mathrm{C}_{0}=0 \mathrm{mg} / \mathrm{L} ; \mathrm{C}\left(\mathrm{O}_{2}\right)=22 \mathrm{ppm} ; \mathrm{TiO}_{2}$ amount $=1 \mathrm{~g} / \mathrm{L} ; C_{\text {feed }}=500 \mathrm{mg} / \mathrm{L}$; initial permeate flux: $J_{\mathrm{p}, \text { in }}=74.2 \mathrm{~L} / \mathrm{m}^{2} \mathrm{~h} ;$ final permeate flux: $J_{\mathrm{p}, \text { fin. }}=29.8 \mathrm{~L} / \mathrm{m}^{2} \mathrm{~h}$; lamp: $125 \mathrm{~W}$ medium pressure Hg immersed lamp; initial $\mathrm{pH} 6.42$; membrane: NTR-7410; $\Delta P=3.5 \mathrm{bar}$ ).

and in the permeate versus irradiation time are reported. It can be noticed that due to the concurrent effect of dilution, adsorption and photodegradation, the accumulation rate in the retentate was, of course, lower than that observed during the other two runs. The concentration of Congo Red in the permeate was virtually zero because the membrane played the role to maintain the substrate in the reacting ambient. The permeate flux $\left(J_{\mathrm{p}}\right)$ throughout the run decreased from the initial value $74.2 \mathrm{~L} / \mathrm{m}^{2} \mathrm{~h}$ to the value of $29.8 \mathrm{~L} / \mathrm{m}^{2} \mathrm{~h}$, and consequently, the dye feeding rate decreased. It is worth noting that the average photodegradation rate $(0.274 \mathrm{mg} / \mathrm{min})$ calculated for the overall run was lower than the average feeding rate $(0.416 \mathrm{mg} / \mathrm{min})$ calculated for the first $180 \mathrm{~min}$, while it was $0.049 \mathrm{mg} / \mathrm{min}$ higher for longer time (average feeding rate $0.225 \mathrm{mg} / \mathrm{min}$ ).

Degradation of Patent Blue was also tested in the continuous system under the same experimental conditions used for Congo Red, and the results are reported in Fig. 13. During the transient state $(250-300 \mathrm{~min}$ in this specific case), the dye accumulated in the photoreactor because the photodegradation rate $(0.570 \mathrm{mg} / \mathrm{min})$ was lower than the feeding rate $(0.863 \mathrm{mg} / \mathrm{min})$. Subsequently, the steady-state

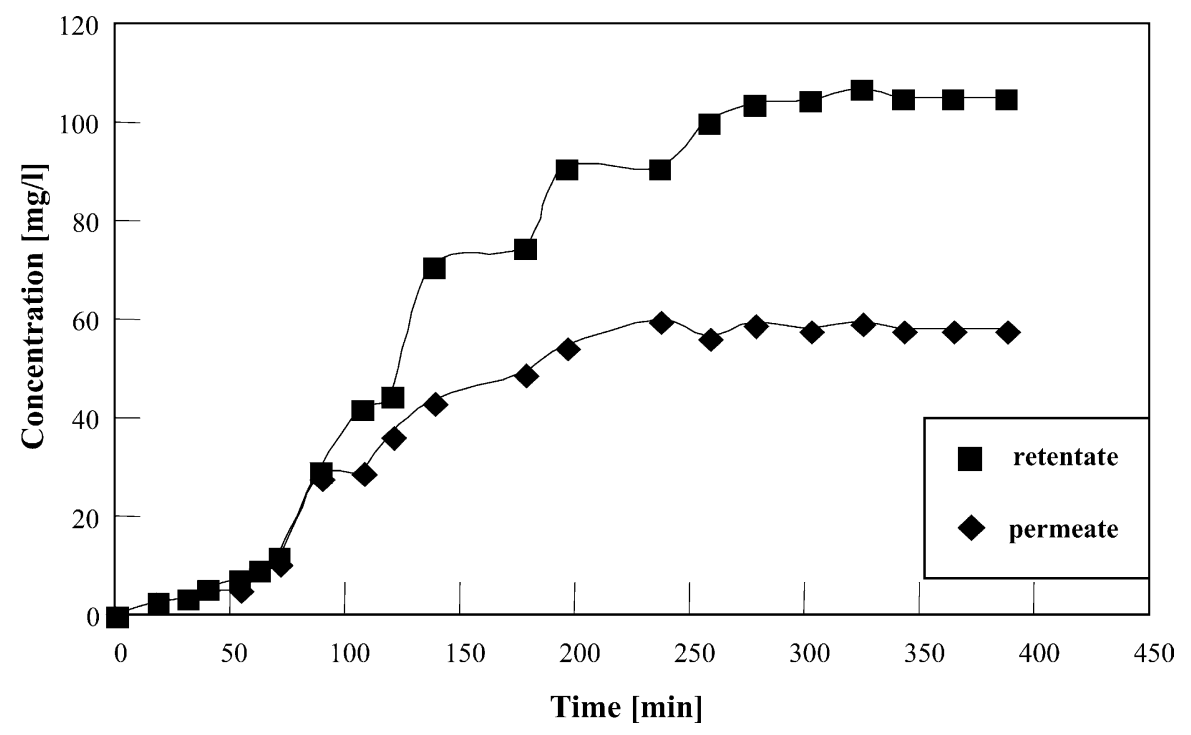

Fig. 13. Concentration of Patent Blue in the retentate and in the permeate versus time for a continuous photodegradation run carried out in the set-up showed in Fig. 5. $\left(V=500 \mathrm{~mL} ; T=303 \mathrm{~K} ; \mathrm{C}_{0}=0 \mathrm{mg} / \mathrm{L} ; \mathrm{C}\left(\mathrm{O}_{2}\right)=22 \mathrm{ppm} ; \mathrm{TiO}_{2}\right.$ amount $=1 \mathrm{~g} / \mathrm{L} ; C_{\text {feed }}=500 \mathrm{mg} / \mathrm{L} ;$ regime permeate flux: $J_{\mathrm{p}}$, regime $=78.4 \mathrm{~L} / \mathrm{m}^{2} \mathrm{~h}$; lamp: $125 \mathrm{~W}$ medium pressure $\mathrm{Hg}$ immersed lamp; initial pH 5.61; membrane: NTR-7410; $\Delta P=7.0$ bar). 
conditions were achieved, owing to the lower permeate flow rate, and no difference was observed between photodegradation and feeding rates. The rejection of NTR-7410 membrane at steady-state conditions with respect to Patent Blue was $44.6 \%$.

Use of the membrane was beneficial because in addition to its role as a barrier for the catalyst, the product, i.e. cleaned-up water (the permeate), contained a very low concentration of dye with respect to the feed. It was ca. $1 \%$ in the case of Congo Red and ca. $11 \%$ in the case of Patent Blue with respect to $500 \mathrm{mg} / \mathrm{L}$ of the feed. It is worth noting that if the membrane was not used, the concentration of the product corresponded in this case to that of the retentate that was ca. 3\% for Congo Red and ca. 22\% for Patent Blue.

Another approach to combine photocatalysis and membrane was to entrap the photocatalyst in the membrane in order to avoid (i) the costly separation of the suspended $\mathrm{TiO}_{2}$ from the liquid, (ii) the possible breaking of the catalyst particles, and (iii) tube plugging and pump wearing out. The performance of a polymeric artificial membrane with the photocatalyst entrapped $\left(\mathrm{CTA}-\mathrm{TiO}_{2}-\mathrm{Al}-10\right)$ was studied using the Congo Red (set-up with external lamp shown in Fig. 6), and the results of a selected run are reported in Fig. 14. The concentration of the pollutant in the retentate remained almost constant throughout the run, and only a small decrease (7.5\%, w/w of Congo Red concentration) was observed in the last part of the experiment (after ca. $300 \mathrm{~min}$ ). The membrane had an average rejection of $80 \%$ at steady-state conditions, but the concentration of the permeate depended on the history of the run. When steady-state conditions were achieved (between 80 and $120 \mathrm{~min}$ ), the rejection of the membrane was ca. $78 \%$ and the run was stopped. When it started again (after ca. $15 \mathrm{~h}$ ), the rejection decreased down to ca. 32\% (between 140 and $180 \mathrm{~min}$ ) due to the adsorption of Congo Red on the membrane. By continuing the selected run without interruptions, a decrease of the concentration of the permeate was observed reaching a rejection equal to ca. $83 \%$, a value very close to that of the first steady-state condition. These findings show the necessity to test membrane rejection during photodegradation without stopping the run.

The photodegradation efficiency of the membrane photoreactor with entrapped $\mathrm{TiO}_{2}$ was compared to that with suspended $\mathrm{TiO}_{2}$. In Fig. 15, the results of a photodegradation run of Congo Red carried out with suspended catalyst are reported (set-up without membrane shown in Fig. 3). The amount of $\mathrm{TiO}_{2}$ used in this system was identical to that entrapped in the polymeric membrane and exposed to the irradiation, although due to the presence of the polymer around the particles of catalyst, it is not easy to establish with accuracy the real amount of photoexcited $\mathrm{TiO}_{2}$ when it is entrapped.

The decrease of Congo Red concentration in the batch photoreactor without membrane was already $35 \%(w / w)$ after $360 \mathrm{~min}$ and $75 \%(\mathrm{w} / \mathrm{w})$ after $18 \mathrm{~h}$, clearly indicating a higher efficiency of the suspended photocatalyst with respect to the entrapped one. Another advantage of the system with the suspended photocatalyst is to avoid the risk of a possible membrane oxidation by ${ }^{\bullet} \mathrm{OH}$ radicals' attack because the photodegradation reaction is physically separated by the membrane. Moreover, the membrane can retain the by-products in the reaction ambient till their photodegradation, enabling only the lower size molecules to pass in the permeate.

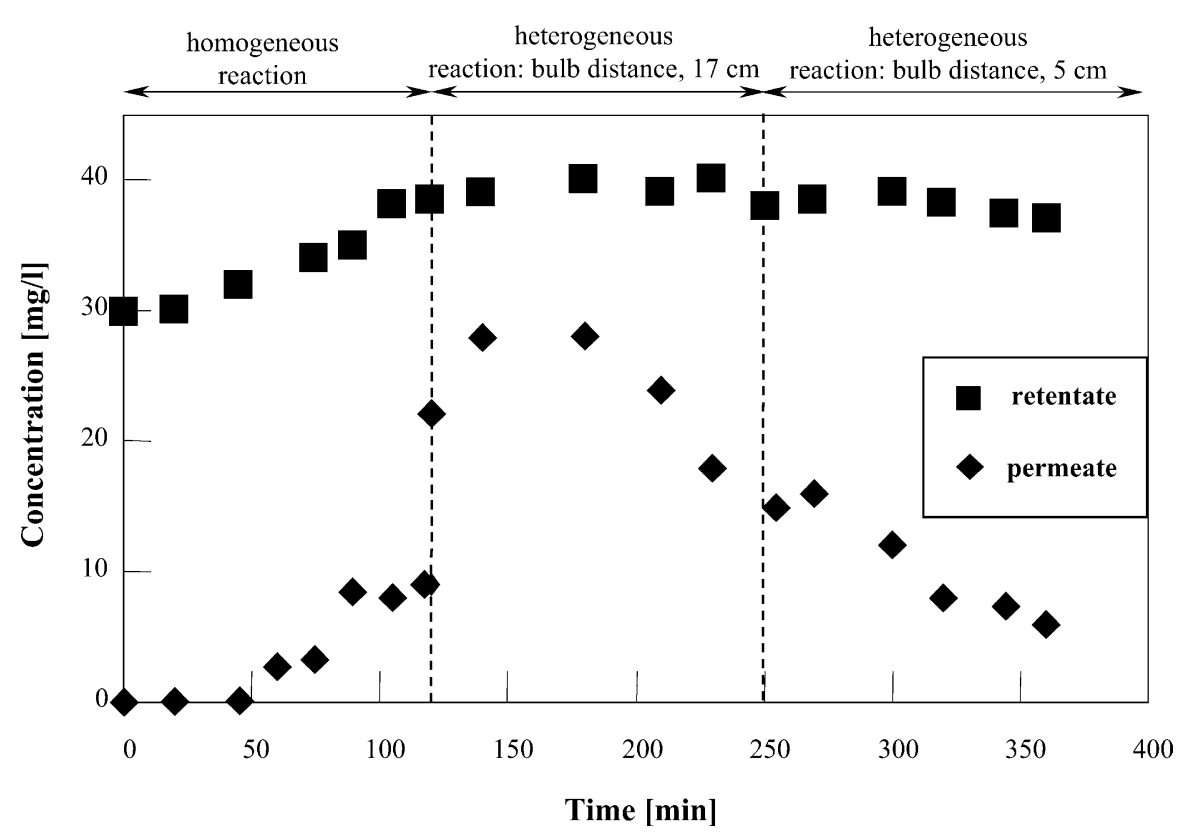

Fig. 14. Concentration of Congo Red in the retentate and in the permeate versus time during a batch photodegradation run carried out in the set-up shown in Fig. 6 with $\mathrm{TiO}_{2}$ entrapped in the CTA-TiO ${ }_{2}-\mathrm{Al}-10$ membrane $(15.4 \mathrm{mg})$. The permeate was recycled. $\left(V=500 \mathrm{~mL} ; T=303 \mathrm{~K} ; \mathrm{C}_{0}=40 \mathrm{mg} / \mathrm{L}\right.$; $\mathrm{C}\left(\mathrm{O}_{2}\right)=22 \mathrm{ppm}$; lamp: $500 \mathrm{~W}$ medium pressure $\mathrm{Hg}$ external lamp; initial $\mathrm{pH} 5.69 ; \Delta P=7$ bar). 


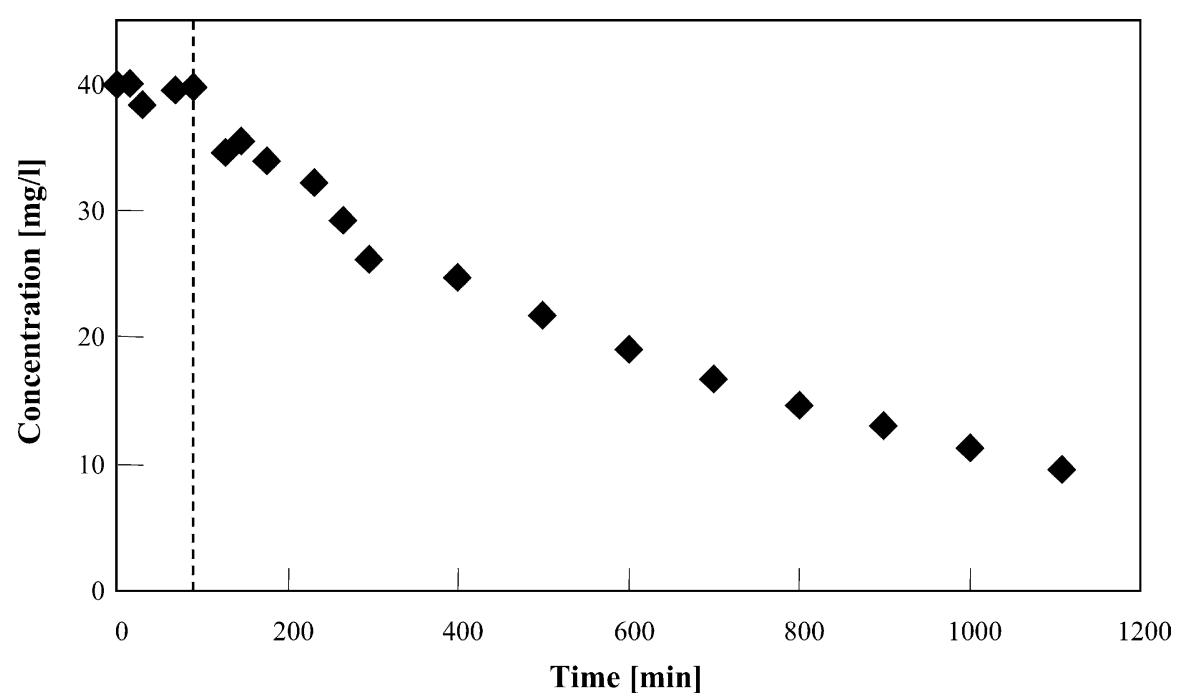

Fig. 15. Concentration of Congo Red versus time for a run carried out in the set-up shown in Fig. 3 before and after the addition of $\mathrm{TiO}_{2}(V=500 \mathrm{~mL}$; $T=303 \mathrm{~K} ; \mathrm{C}_{0}=40 \mathrm{mg} / \mathrm{L} ; \mathrm{C}\left(\mathrm{O}_{2}\right)=22 \mathrm{ppm} ; \mathrm{TiO}_{2}$ amount $=30.8 \mathrm{mg} / \mathrm{L}$; lamp: $500 \mathrm{~W}$ medium pressure $\mathrm{Hg}$ external lamp; distance from the bulb of the lamp and the photoreactor $=5 \mathrm{~cm}$; initial $\mathrm{pH} 5.65$ ).

\section{Conclusions}

The photodegradation of Patent Blue and Congo Red dyes dissolved in water was studied by using $\mathrm{TiO}_{2}$ Degussa P25 as the catalyst and by suitably combining some factors, i.e. the configuration and the working condition of the plant, the kind of radiation source and its position with respect to the reacting mixture, the manner of using the catalyst, the operational pressure of the plant, the initial concentration of the dyes, etc.

The immersed UV lamp gave a photodegradation rate of Congo Red in the batch photoreactor without membrane ca. 50 times higher than that found with the external lamp.

By increasing the initial concentration of Patent Blue in the reacting suspension, a Langmuir-Hinshelwood kinetics was observed with a photodegradation rate that did not change significantly, but only time needed to degrade completely the pollutant increased by increasing its concentration.

To overcome the observed lower photodegradation rate without membrane with respect to that with the membrane both for Congo Red ( $v_{\text {without membrane }}=0.274 \mathrm{mg} / \mathrm{min}$, $v_{\text {with membrane }}=0.204 \mathrm{mg} / \mathrm{min}$ ) and for Patent Blue $\left(v_{\text {without membrane }}=0.114 \mathrm{mg} / \mathrm{min}, v_{\text {with membrane }}=0.0373\right.$ $\mathrm{mg} / \mathrm{min}$ ), a minimisation of the volume of the recycling loop with respect to the irradiated volume in the photocatalytic membrane reactor is required.

Moreover, for both processes, photodegradation rate of Congo Red was higher probably because of its higher adsorption onto the catalyst surface.

Use of the photocatalyst in suspended form was more efficient than $\mathrm{TiO}_{2}$ entrapped in a polymeric membrane.

It was possible to treat successfully highly concentrated solutions $(500 \mathrm{mg} / \mathrm{L})$ of both dyes by means of a continuous process with suspended photocatalyst. This approach could be interesting by an application point of view to use photocatalysis coupled with membrane technology for the decontamination of actual effluents produced in the dyes-related industries.

\section{References}

[1] H. Zollinger, Color Chemistry: Synthesys, Properties and Applications of Organic Dyes and Pigments, VCH Publishers, New York, 1987.

[2] E. Bartholini, in: L. Palmisano (Ed.), Processi e Metodologie per il Trattamento delle Acque, Spiegel, Milano, 2000, p. 283.

[3] L. Chen, Effects of factors and interacted factors on the optimal decolorization process of methyl orange by ozone, Water Res. 34 (2000) 974-982.

[4] J. Bandara, C. Morrison, J. Kiwi, C. Pulgarin, P. Peringer, Degradation/decoloration of concentrated solutions of Orange II. Kinetics and quantum yield for sunlight induced reactions via Fenton type reagents, J. Photochem. Photobiol. 99 (1996) 57 66.

[5] W. Feng, D. Nansheng, H. Helin, Degradation mechanism of azo dye C.I. reactive red 2 by iron powder reduction and photoxidation in aqueous solution, Chemosphere 41 (2000) 1233-1238.

[6] D.F. Ollis, E. Pelizzetti, N. Serpone, in: N. Serpone, E. Pelizzetti (Eds.), Photocatalysis Fundamentals and Applications, Wiley, New York, 1986, p. 603.

[7] D.F. Ollis, H. Al-Ekabi, Photocatalytic Purification and Treatment of Water and Air, Elsevier, Amsterdam, 1993.

[8] V. Augugliaro, V. Loddo, G. Marcì, L. Palmisano, M.J. López-Muñoz, Photocatalytic oxidation of cyanides in aqueous titanium dioxide suspensions, J. Catal. 166 (1997) 272-283.

[9] V. Augugliaro, A. Bianco Prevot, V. Loddo, G. Marcì, L. Palmisano, E. Pramauro, M. Schiavello, Photodegradation kinetics of aniline, 4-ethylaniline, and 4-chloroaniline in aqueous suspension of polycrystalline titanium dioxide, Res. Chem. Intermed. 26 (2000) 413 426 
[10] M.R. Hoffmann, S.T. Martin, W. Choi, D.W. Bahnemann, Environmental applications of semiconductor photocatalysis, Chem. Rev. 95 (1995) 69-96.

[11] P.V. Kamat, Photochemistry on nonreactive and reactive (semiconductor) surfaces, Chem. Rev. 93 (1993) 267-300.

[12] K. Vinodgopal, I. Bedja, S. Hotchandani, P.V. Kamat, A photocatalytic approach for the reductive decolorization of textile azo dyes in colloidal semiconductor suspensions, Langmuir 10 (1994) 17671771.

[13] C. Nasr, K. Vinodgopal, S. Hotchandani, A.K. Chattopadhyay, P.V. Kamat, Photocatalytic reduction of azo dyes naphthol blue black and disperse blue 79, Res. Chem. Intermed. 23 (1997) 219-232.

[14] H. Chun, W. Yizhong, Decolorization and biodegradability of photocatalytic treated azo dyes and wool textile wastewater, Chemosphere 39 (1999) 2107-2115.

[15] K. Tanaka, K.K. Padermpole, T. Hisanaga, Photocatalytic degradation of commercial azo dyes, Water Res. 34 (2000) 327-333.

[16] C. Zhu, L. Wang, L. Kong, X. Yang, L. Wang, S. Zheng, F. Chen, F. Mai Zhi, H. Zong, Photocatalytic degradation of AZO dyes by supported $\mathrm{TiO}_{2}+\mathrm{UV}$ in aqueous solution, Chemosphere 41 (2000) 303-309.

[17] V. Augugliaro, C. Baiocchi, A. Bianco-Prevot, E. García-López, V. Loddo, S. Malato-Rodríguez, G. Marcì, L. Palmisano, E. Pramauro, Sunlight photocatalytic degradation of azo-dyes in aqueous suspension of polycrystalline $\mathrm{TiO}_{2}$, Fresenius Environ. Bull. 11 (2002) 459-465.
[18] V. Augugliaro, C. Baiocchi, A. Bianco-Prevot, V. Augugliaro, C. Baiocchi, A. Bianco-Prevot, E. García-López, V. Loddo, S. Malato-Rodríguez, G. Marcì, L. Palmisano, M. Pazzi, E. Pramauro, Azo-dyes photocatalytic degradation in aqueous suspension of $\mathrm{TiO}_{2}$ under solar irradiation, Chemosphere 49 (2002) 1223-1230.

[19] A.M. Brites Alves, M.N. De Pinho, Ultrafiltration for colour removal of tannery dyeing wastewaters, Desalination 130 (2000) 147154.

[20] B. van der Bruggen, B. Daems, D. Wilms, C. Vandecasteele, Mechanisms of retention and flux decline for the nanofiltration of dye baths from the textile industry, Separation Purif. Technol. 22-23 (2001) 519-528.

[21] B. van der Bruggen, I. De Vreese, C. Vandecasteele, Water reclamation in the textile industry: nanofiltration of dye baths for wool dyeing, Ind. Eng. Chem. Res. 40 (2001) 3973-3978.

[22] A. Lopez, G. Ricco, G. Mascolo, G. Tiravanti, A.C. Di Pinto, R. Passino, Biodegradability enhancement of refractory pollutants by ozonation: a laboratory investigation on an azo-dyes intermediate, Wat. Sci. Tech. 38 (1998) 239-245.

[23] R. Molinari, M. Mungari, E. Drioli, A. Di Paola, V. Loddo, L. Palmisano, M. Schiavello, Study on a photocatalytic membrane reactor for waste minimisation, Catalysis Today 55 (2000) 71-78.

[24] R. Molinari, L. Palmisano, E. Drioli, M. Schiavello, Studies on various reactor configurations for coupling photocatalysis and membrane processes in water purification, J. Membr. Sci. 206 (2002) 399415. 